\title{
PENERAPAN METODE MEAN ABSOLUTE ERROR (MEA) DALAM ALGORITMA REGRESI LINEAR UNTUK PREDIKSI PRODUKSI PADI
}

\author{
Andik Adi Suryanto, Asfan Muqtadir \\ Jurusan Teknik Informatika, FT, Universitas PGRI Ronggolawe \\ Correspondence Author: andikadisuryanto@gmail.com
}

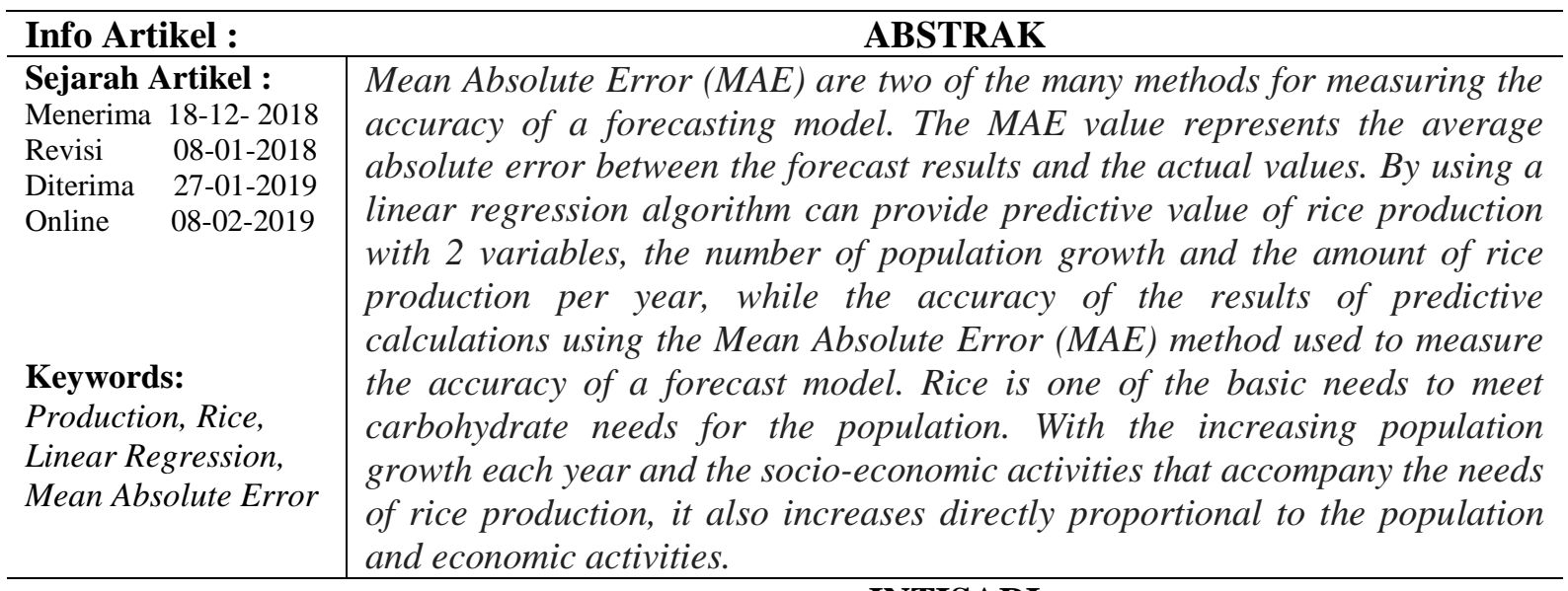

Kata Kunci :

Padi, Regresi Linear,

Mean Absolute Error
Mean Absolute Error (MAE) adalah salah satu metode yang digunakan untuk mengukur tingkat keakuratan model peramalan. Hasil Mean Absolute Error menunjukkan nilai rata-rata kesalahan multak atau absolut dari nilai sebenarnya dengan nilai peramalan. Dengan menggunakan algoritma regresi linear dapat memberikan nilai prediksi produksi padi dengan 2 variabel jumlah pertumbuhan penduduk dan jumlah produksi padi pertahun, sedangan keakuratan dari hasil perhitungan prediksi menggunakan metode Mean Absolute Error (MAE) yang gunakan untuk mengukur tingkat keakuratan suatu model peramalan. Padi adalah salah satu kebutuhan pokok untuk memenuhi kebutuhan karbohidrat bagi penduduk. Dengan meningkatnya pertumbuhan penduduk tiap tahunnya dan kegiatan sosial ekonomi yang menyertainya kebutuhan Produksi padi makin meningkat pula berbanding lurus jumlah penduduk dan kegiatan ekonomi.

\section{PENDAHULUAN}

Regresi linear merupakan metode yang dapat digunakan untuk mengukur minmal 2 variabel , cara mengukur datanya dengan menggunakan variabel dependen dan variable independent yang digambar melalui Korelasi antar 2 variabel tersebut melalui garis lurus (Susanti dkk, 2010).

Padi merupakan salah satu kebutuhan pangan primer penduduk untuk memenuhi kebutuhan karborhidrat. Dengan perkembangan jumlah penduduk meningkat tiap tahun, maka kebutuhan kebutuhan produksi meningkat pula berbanding lurus dengan jumlah pertumbuhan penduduk (Yusuf, 2010) .

Berdasarkan permasalahan tersebut peneliti menggunakan salah satu metode peramalan yaitu regresi linear untuk memprediksi kebutuhan produksi padi. Untuk keakuratan hasil prediksi menggunakan Mean Absolute Error dan Mean Absolute Error Percentage Error. 


\section{METODE}

\subsection{Regresi Linear}

Dalam data mining fungsi merupakan salah satu bagian dari fungsi minor. Prediksi adalah cara untuk mencari kemungkinan hasil pada masa akan datang.

Pada teknologi data mining, berdasatkan bukti dan temuan pada data yang digunakan metode peramalan dapat memprediksi kemungkinan pada masa datang. Perhitungan matematik dan statistik berperan erat dalam proses prediksi.

Langkah prediksi dapat dilakukan menggunakan perhitungan rumus regresi linier. Rumus regresi ada 2 macam sebagai langkah proses analisis prediksi yaitu, regresi linear ganda dan regresi linear tunggal. Dengan analisis statistik dapat mengetahui korelasi hasil analisa prediksi dengan hipotesis hasil .

Regresi Linier merupakan cara untuk mengukur hubungan korelasi antara dua variabel atau lebih yang digunakan untuk data prediksi melalui garis lurus (Susanto dkk, 2010)., Cara mempelajari bagaimana hubungan variabel-variabel pada proses peramalan data dapat menggunakan prediksi regresi linier

Variabel adalah ukuran yang dapat berubah-ubah nilainya. Ada 2 tipe variabel dalam regresi linier yaitu: variabel pemberi pengaruh dan variabel terpengaruh. Variabel pemberi pengaruh digunakan sebagai sebab, sedangkan variabel terpengaruh sebagai akibat.

\subsection{Mean Absolute Error (MAE)}

Mean Absolute Error (MAE) adalah salah satu metode yang digunakan untuk mengukur tingkat keakuratan model peramalan. Nilai MAE menunjukan rata - rata kesalahan (error) absolut antara hasil peramalan/prediksi dengan nilai riil (Subagyo, 1986).

Secara rumus MAE dijelaskan sebagai berikut,

$$
\mathrm{MAE}=\frac{1}{n} \sum_{i=1}^{n}\left|f_{i}-y_{i}\right|
$$

Dimana :

$f_{i}$ adalah nilai hasil peramalan,

$y_{i}$ adalah nilai sebenarnya, dan

$n$ adalah jumlah data.

Berdasarkan rumus 1 di atas, MAE menghitung rata - rata error dengan memberikan bobot yang sama untuk seluruh data $(i=1 \ldots n)$ secara intuitif. Untuk evaluasi model peramalan, MAE lebih intuitif dalam memberikan rata - rata error dari keseluruhan data. Dalam kasus ini pemilihan MAE menjadi tepat karena seluruh data diberikan bobot yang sama.

Dalam kasus klasifikasi biner, dimana hanya terdapat dua kelas dengan label kelas 1 dan 0 , dalam penggunaan MAE. Hal ini karena nilai error hanya mempunyai dua kemungkinan, 1 jika prediksi kelas berbeda dengan kelas sebenarnya dan 0 jika prediksi benar.

\subsection{Padi}

Padi merupakan bahan pokok sehari-hari pada mayoritas kebanyakan di negara indonesia. Pada dikenal sebagai sumber karbohidrat. Bagi penduduk Indonesia padi merupakan makanan pokok dan kebutuhan bahan makanan primer tidak dapat digantikan bahan makanan yang lain (Aak, 1990). Komoniditas pemenuhan kaborhidrat bagi penduduk dapat diperoleh pada hasil pertanian yaitu padi yang mengalami peningkatan tiap tahunnya akibat dari peningkatan jumlah penduduk serta berkembangnya kegiatan ekonomi dan sosial (Yusuf, 2010) 


\section{HASIL DAN PEMBAHASAN}

\subsection{Pembahasan}

Data yang digunakan untuk menunjang penelitian ini meliputi data penduduk dan data produksi padi tiap tahun. Data yang digunakan merupakan data yang diterbitkan Badan Pusat Statisitik Kabupaten.

Tabel 1. Kerangka sistem pemanfaatan metode Mean Absolute Error

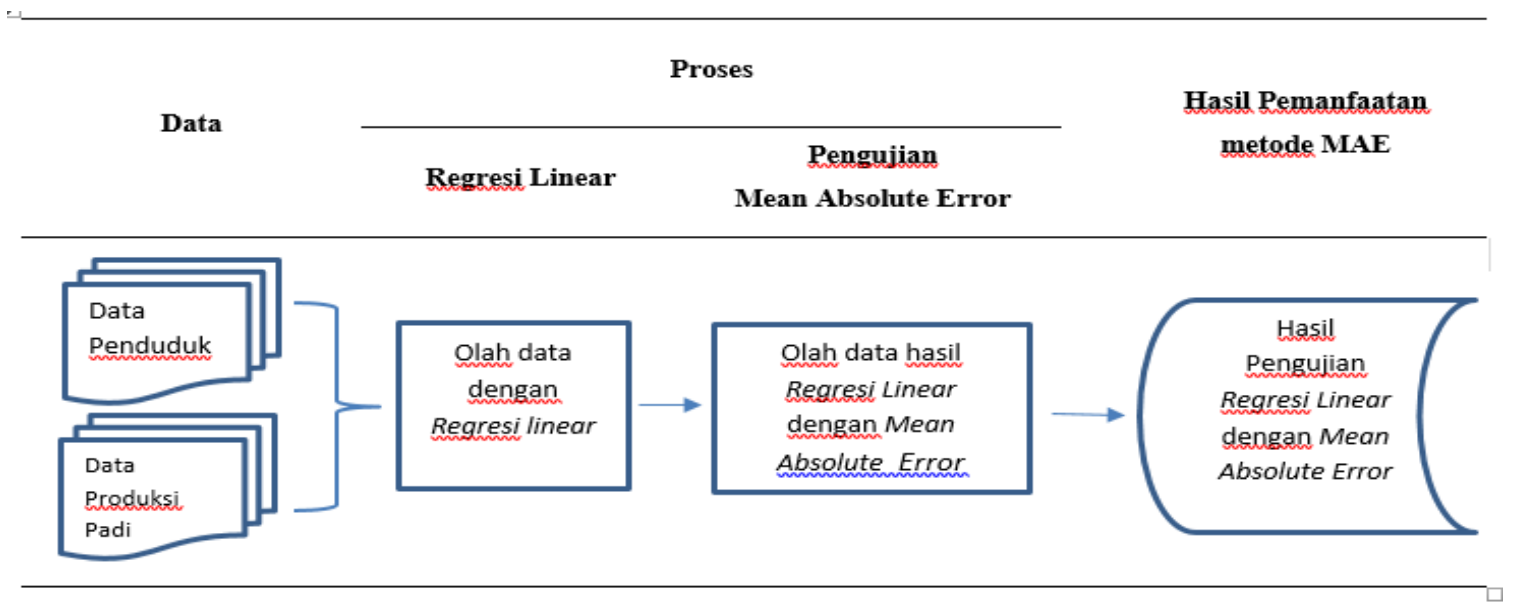

Pada tabel 1 merupakan Kerangka sistem penerapan metode Mean Absolute Error dalam algoritma Regresi Linear. Pengolahan data penduduk dan data produksi padi dengan menggunakan metode Regresi Linear akan memperoleh data prediksi produksi pada tahun berikutnya. Untuk mengetahui keakuratan hasil Regresi Linear dengan menguji dengan Metode Absolute Error (MEA), dengan menggunakan Metode Absolute Error (MEA) dapat diperoleh nilai keakurasi dari hasil Regresi Linear.

\subsection{Hasil}

Penyelesaian pengunaan regresi linear sederhana untuk memprediksi kebutuhan produksi padi seperti tahapan dibawah ini :

1. Penentuan Tujuan

Penggunan metode regresi linear sederhan ini untuk memprediksi jumlah produksi padi.

2. Identifikasi variable penyebab dan akibat

Dari data yang diperoleh digolongan menjadi 2 variabel faktor penyebab (X) dan variabel akibat (Y) sebagai berikut :

Variabel faktor penyebab (X) = Jumlah penduduk

Variabel akibat $(\mathrm{Y}) \quad=$ Jumlah Produksi Padi

3. Pengumpulan data

Data yang digunakan mulai tahun 2000 sampai 2017, sebagai berikut 
Tabel 2. Tabel Jumlah Penduduk dan Produksi Padi

\begin{tabular}{ccc}
\hline Tahun & $\begin{array}{c}\text { Jumlah } \\
\text { Penduduk } \\
\text { Registrasi } \\
(\mathrm{X})\end{array}$ & $\begin{array}{c}\text { Jumlah } \\
\text { Produksi Padi } \\
\text { Dalam } \\
\text { Kwintal (Y) }\end{array}$ \\
\hline 2000 & 1021920 & 3898622 \\
\hline 2001 & 1027546 & 3802048 \\
\hline 2002 & 1035341 & 3849083 \\
\hline 2003 & 1058979 & 3820119 \\
\hline 2004 & 1042718 & 3959801 \\
\hline 2005 & 1074109 & 4075379 \\
\hline 2006 & 1124508 & 4075390 \\
\hline 2007 & 1127416 & 4585170 \\
\hline 2008 & 1137708 & 4543510 \\
\hline 2009 & 1139052 & 4710640 \\
\hline 2010 & 1259996 & 5115100 \\
\hline 2011 & 1258816 & 5176300 \\
\hline 2012 & 1290394 & 5890660 \\
\hline 2013 & 1288975 & 4888390 \\
\hline 2014 & 1291665 & 5376630 \\
\hline 2015 & 1304080 & 5463100 \\
\hline 2016 & 1315155 & 5843060 \\
\hline 2017 & 1267886 & 5894210 \\
\hline & & \\
\hline
\end{tabular}

4. Model persamaan regresi linear sederhana $\mathrm{Y}=\mathrm{a}+\mathrm{bX}$

5. Hasil prediksi terhadap variabeal penyebab atau akibat produksi padi tiap tahun dari tahun 2000 - 2017 menggunakan regresi linear sederhana yaitu

Tabel 3. Hasil Prediksi pertahun

\begin{tabular}{rcrr}
\hline Tahun & $\begin{array}{c}\text { Jumlah } \\
\text { Penduduk } \\
\text { Registrasi } \\
(\mathrm{X})\end{array}$ & $\begin{array}{c}\text { Jumlah } \\
\text { Produksi Padi } \\
\text { Dalam } \\
\text { Kwintal (Y) }\end{array}$ & $\begin{array}{r}\text { Nilai Prediksi } \\
\text { Produksi Padi } \\
\text { dalam Kwintal }\end{array}$ \\
\hline 2000 & 1021920 & 3898622 & 0 \\
\hline 2001 & 1027546 & 3802048 & 3802048 \\
\hline 2002 & 1035341 & 3849083 & 3828080 \\
\hline 2003 & 1058979 & 3820119 & 3814568 \\
\hline 2004 & 1042718 & 3959801 & 3863785 \\
\hline 2005 & 1074109 & 4075379 & 3996009 \\
\hline 2006 & 1124508 & 4075390 & 4092447 \\
\hline 2007 & 1127416 & 4585170 & 4320132 \\
\hline 2008 & 1137708 & 4543510 & 4433516 \\
\hline
\end{tabular}




\begin{tabular}{llll}
\hline 2009 & 1139052 & 4710640 & 4514351 \\
\hline 2010 & 1259996 & 5115100 & 5178435 \\
\hline 2011 & 1258816 & 5176300 & 5173376 \\
\hline 2012 & 1290394 & 5890660 & 5539802 \\
\hline 2013 & 1288975 & 4888390 & 5368272 \\
\hline 2014 & 1291665 & 5376630 & 5382631 \\
\hline 2015 & 1304080 & 5463100 & 5457309 \\
\hline 2016 & 1315155 & 5843060 & 5577583 \\
\hline 2017 & 1267886 & 5894210 & 5347763 \\
\hline
\end{tabular}

Pada tabel 3 merupakan hasil prediksi dari persamaan regresi linear. Contohnya pada tahun 2017 hasil prediksi 5347763 kwintal hari produksi padinya.

\subsection{Hasil Mean Absolute Error (MAE)}

Penggunaan Mean Absolute Error dalam penelitian ini untuk menguji hasil prediksi dengan menggunakan Regresi linear Sederhana. Adapun hasil perhitungan dapat dilihat pada tabel 4 .

Tabel 4. Hasil Mean Absolute Error

\begin{tabular}{|r|r|r|r|r|r|r|}
\hline No & Tahun & $\begin{array}{c}\text { Jumlah } \\
\text { Penduduk } \\
\text { Registrasi } \\
\text { (X) }\end{array}$ & $\begin{array}{c}\text { Jumlah } \\
\text { Produksi } \\
\text { Padi } \\
\text { Dalam } \\
\text { Kwintal } \\
\text { (Y) }\end{array}$ & $\begin{array}{c}\text { Nilai } \\
\text { Prediksi } \\
\text { (y1) }\end{array}$ & (y-y1) & $\begin{array}{c}\text { MAE } \\
(\mathbf{y}-\mathbf{y} \mathbf{~} / \\
\mathbf{y})\end{array}$ \\
\hline 1 & 2000 & 1021920 & 3898622 & 0 & 3898622 & 1,00000 \\
\hline 2 & 2001 & 1027546 & 3802048 & 3802048 & 0 & 0,00000 \\
\hline 3 & 2002 & 1035341 & 3849083 & 3828080 & 21003 & 0,00546 \\
\hline 4 & 2003 & 1058979 & 3820119 & 3814568 & 5551 & 0,00145 \\
\hline 5 & 2004 & 1042718 & 3959801 & 3863785 & 96016 & 0,02425 \\
\hline 6 & 2005 & 1074109 & 4075379 & 3996009 & 79370 & 0,01948 \\
\hline 7 & 2006 & 1124508 & 4075390 & 4092447 & 17057 & 0,00419 \\
\hline 8 & 2007 & 1127416 & 4585170 & 4320132 & 265038 & 0,05780 \\
\hline 9 & 2008 & 1137708 & 4543510 & 4433516 & 109994 & 0,02421 \\
\hline 10 & 2009 & 1139052 & 4710640 & 4514351 & 196289 & 0,04167 \\
\hline 11 & 2010 & 1259996 & 5115100 & 5178435 & 63335 & 0,01238 \\
\hline 12 & 2011 & 1258816 & 5176300 & 5173376 & 2924 & 0,00056 \\
\hline 13 & 2012 & 1290394 & 5890660 & 5539802 & 350858 & 0,05956 \\
\hline 14 & 2013 & 1288975 & 4888390 & 5368272 & 479882 & 0,09817 \\
\hline 15 & 2014 & 1291665 & 5376630 & 5382631 & 6001 & 0,00112 \\
\hline 16 & 2015 & 1304080 & 5463100 & 5457309 & 5791 & 0,00106 \\
\hline 17 & 2016 & 1315155 & 5843060 & 5577583 & 265477 & 0,04543 \\
\hline 18 & 2017 & 1267886 & 5894210 & 5347763 & 546447 & 0,09271 \\
\hline & & & Total MAE & & & 1,48950 \\
\hline
\end{tabular}

Pada tabel 4 diperoleh hasil perhitungan Mean Absolute Error (MAE) dengan nilai 1,48950.

Jadi, prediksi kebutuhan produksi padi pada tahun 2017 sebesar 5347763 kwintal dengan nilai Mean Absolute Error sebesar 1,48950. 


\section{KESIMPULAN}

Pemanfaatan metode regresi linear sederhana dapat memperoleh hasil perhitungan produksi padi pada tahun 2017 prediksi produksi padi sebesar 5347763 kwintal. Pengujian keakuratan peramalan atau prediksi metode regresi linear menggunakan metode Mean Absolute Error (MEA) dengan nilai 1,48950 .

\section{DAFTAR PUSTAKA}

Aak. 1990. Budidaya Tanaman Padi. Kanisius. Yogyakarta. pp: 15, 27

Pakaja, 2012, Peramalan Penjualan Mobil Menggunakan Jaringan Syaraf Tiruan dan Certainty Faktor, EECCIS, Vols.6, No.1,.

Subagyo, Pangestu, 1986, Forecasting Konsep dan Aplikasi, Yogyakarta, BPPE UGM.

Susanto, Sani dan Suryadi, Dedy, 2010, Pengantar Data Mining Mengali Pengetahuan dari Bongkahan Data, CV ANDI Offset, Yogyakarta.

Yusuf, A, 2010, Teknologi Budidaya Pada Sawah Mendukung SL-PTT BPTP, Sumatera Utara 